\title{
BMJ Open Patients' perspectives of tuberculosis treatment challenges and barriers to treatment adherence in Ukraine: a qualitative study
}

\author{
Omowunmi Aibana (D) , ${ }^{1}$ Emily Dauria, ${ }^{2}$ Tetiana Kiriazova, ${ }^{3}$ Olena Makarenko, ${ }^{3}$ \\ Mariya Bachmaha, ${ }^{4}$ Natasha Rybak, ${ }^{5}$ Timothy Palen Flanigan, ${ }^{5}$ Vasyl Petrenko, ${ }^{6}$ \\ Anne E Becker, ${ }^{7}$ Megan B Murray ${ }^{7}$
}

To cite: Aibana 0, Dauria E, Kiriazova T, et al. Patients' perspectives of tuberculosis treatment challenges and barriers to treatment adherence in Ukraine: a qualitative study. BMJ Open 2020;10:e032027. doi:10.1136/ bmjopen-2019-032027

- Prepublication history and additional material for this paper are available online. To view these files, please visit the journal online (http://dx.doi. org/10.1136/bmjopen-2019032027).

Received 29 May 2019 Revised 18 November 2019 Accepted 14 January 2020

Check for updates

(C) Author(s) (or their employer(s)) 2020. Re-use permitted under CC BY-NC. No commercial re-use. See rights and permissions. Published by BMJ.

For numbered affiliations see end of article.

Correspondence to Dr Omowunmi Aibana; omowunmi.aibana@uth.tmc.edu

\section{ABSTRACT}

Objectives To understand the challenges faced by patients with tuberculosis (TB) and factors that influence TB treatment adherence in Ukraine.

Design Qualitative study.

Setting TB treatment facilities in Kyiv Oblast, Ukraine. Participants Sixty adults who had undergone treatment for drug-sensitive TB between June 2012 and August 2015.

Methods We conducted semistructured, in-depth, individual interviews among a purposively selected clinical sample of patients previously treated for drug-sensitive TB. Interview content encompassed WHO's framework for barriers to adherence to long-term therapies and included questions about patient preferences and motivators concerning treatment adherence. We examined treatment experience across strata defined by previously identified risk correlates of non-adherence.

Results Among 60 participants, 19 (32.8\%) were HIV positive, $12(20.3 \%)$ had substance use disorder and 9 (15.0\%) had not completed TB treatment. Respondents discussed the psychological distress associated with hospital-based TB care, as well as perceived unsupportive, antagonistic interactions with TB providers as major challenges to treatment adherence. An additional barrier to successful treatment completion included the financial toll of lost income during TB treatment, which was exacerbated by the additional costs of ancillary medications and transportation to ambulatory TB clinics. The high pill burden of TB treatment also undermined adherence. These challenges were endorsed among participants with and without major risk factors for nonadherence.

Conclusions Our findings highlight important barriers to TB treatment adherence in this study population and suggest specific interventions that may be beneficial in mitigating high rates of poor treatment outcomes for TB in Ukraine.

\section{INTRODUCTION}

Tuberculosis (TB) remains a significant global health problem with an estimated 10 million new cases diagnosed in 2018. ${ }^{1}$ TB control is especially challenging in Eastern European
Strengths and limitations of this study

- We analysed qualitative data from semistructured, individual interviews conducted among a large sample of patients with lived experience of tuberculosis (TB) in Kyiv Oblast.

- The study aimed to augment understanding of patient experiences to illuminate barriers to adherence to drug-sensitive TB treatment in Ukraine.

- The study complements and contextualises available evidence pointing to a high risk of lost to followup among patients with TB in this setting.

- This study is limited by selective sampling of patients with TB in only one region of Ukraine.

- Additional studies are needed to explore provider perspectives on measures to improve adherence and TB treatment outcomes in Ukraine.

countries like Ukraine, which has one of the highest burdens of multidrug-resistant TB (MDR-TB) worldwide with an estimated $29 \%$ of new TB cases being MDR. ${ }^{2}$ Following the dissolution of the Soviet Union, many former Soviet Union countries experienced significant reduction in healthcare financing with a concomitant substantial rise in individual out-of-pocket healthcare costs. ${ }^{3}$ Amidst this post-Soviet era decline in public health and safety net programmes, many countries faced rising poverty levels, high incarceration rates, skyrocketing injection drug use and a rapid rise in HIV incidence, all of which fuelled the TB epidemic in Eastern Europe in the 1990s. ${ }^{4-9}$

Whereas TB incidence is now declining in parts of Eastern Europe, Ukraine remains among countries in this region with ongoing rise in TB incidence, which has increased from 41.7 per 100000 in 1995 to 80 per 100000 in 2018. ${ }^{12} 10$ TB burden is unevenly distributed with the highest incident rates in the penitentiary system throughout Ukraine and in the 
south-eastern region. ${ }^{11}$ In virtually all parts of Ukraine, rate of incident TB among rural residents is $20 \%-30 \%$ higher than among urban residents. ${ }^{11} \mathrm{~TB}$ incidence as well as associated mortality remains higher for men compared with women, ${ }^{11}$ and rising rates of HIV and TB coinfection indicate a convergence of HIV and TB epidemics in Ukraine. ${ }^{211}$

The Ukraine's National TB Program (UNTP) issues standard procedures and guidelines for TB programme activities. ${ }^{12} \mathrm{~TB}$ service is organised as a centralised, vertical system made up of specialised hospitals and outpatient clinics. The system relies heavily on passive case finding with diagnosis and management of TB primarily undertaken by TB specialists. Although Ukraine has adopted the WHO recommended Directly Observed Therapy Short-Course (DOTS) programme for TB management, the national treatment success rate for drug-sensitive TB (DSTB) in 2017 was $76 \%,{ }^{2}$ significantly lower than the WHO recommended target of at least $90 \%^{13}$; and studies have reported MDR-TB treatment success rates below $25 \%$ among patients with TB treated in Kyiv, the capital of Ukraine. ${ }^{14} 15$

Failure to complete TB treatment may result in poor patient outcomes, and previous studies have identified many patient-related risk factors for loss to follow-up during treatment including unemployment, substance use disorder (SUD) and HIV. ${ }^{16-24}$ Qualitative studies from diverse social settings across the economic spectrum have also described barriers to TB treatment adherence such as stigma, financial burden, inadequate TB knowledge and treatment side effects. ${ }^{192} 25{ }^{26}$ Qualitative evidence from Eastern Europe has revealed additional factors such as hospital-based treatment, lack of social support and poor patient-provider communication as drivers of poor treatment adherence, particularly among patients with MDR-TB. ${ }^{27-29}$

Prior analyses of UNTP have enumerated institutional and political barriers to successful DOTS implementation $^{1030}$; however, only one qualitative study to date has assessed patient perspectives concerning barriers to treatment adherence in the specific context of TB care delivery in Ukraine. ${ }^{31}$ Notably, the WHO highlights patient-centred approaches to TB care as a critical component of TB control efforts. ${ }^{32}$ These approaches recognise patients as the principal figures in the care continuum and consider patients' personal and social circumstances in delivering care. ${ }^{32}$

We conducted a qualitative study exploring patients' experiences during $\mathrm{TB}$ treatment to identify patient perspectives regarding critical challenges and associated factors that influence TB treatment adherence in Ukraine.

\section{METHODS}

\section{Study setting}

We conducted this study in the Kyiv Oblast, Ukraine, where the notification rate for pulmonary TB in 2017 was approximately 79 per 100000 . Patients receive TB diagnostic evaluation and treatment free of charge according to UNTP guidelines. ${ }^{12}$ All administrative regions of Ukraine have dedicated TB hospitals where, prior to 2014, all patients diagnosed with DSTB were admitted to receive 2 months of inpatient intensive phase therapy with four drugs (isoniazid, rifampin, pyrazinamide, ethambutol), followed by 4 months of outpatient therapy with two drugs (isoniazid and rifampin) daily. Although new guidelines disseminated in 2014 recommended complete outpatient management of DSTB, ${ }^{12}$ many regions, including Kyiv Oblast, continue to hospitalise patients for the initial 2 months of treatment. Guidelines further stipulate daily directly observed therapy in TB clinics during the outpatient phase of DSTB treatment. In Kyiv Oblast, some patients arrange to receive medication weekly to better accommodate their schedules.

\section{Inclusion criteria}

Eligible participants included all adult patients $(\geq 18$ years) treated for DSTB in Kyiv Oblast between June 2012 and study initiation in August 2015. We excluded individuals younger than 18 years of age and those treated for drug-resistant TB because paediatric and resistant TB requires different management protocols.

\section{Sampling}

From a literature review and preliminary quantitative analysis of Kyiv Oblast data, we identified HIV infection, alcohol use disorder and SUD as major determinants of loss to follow-up during DSTB treatment. Therefore, we used a purposive sampling strategy to maximise variability regarding participants' HIV status and presence or absence of alcohol or SUD. To achieve theme saturation, we aimed for 12-16 patients per stratum for a total sample size of approximately 48-64. Within each stratum, we also attempted to purposively sample patients who had finished TB treatment and those who had not completed treatment in order to maximise the breadth of patient experience in enablers and barriers to treatment adherence. We did not prespecify a target for patients who had not completed treatment because we anticipated they might be unreachable.

We reviewed 147 consecutive medical records from the Kyiv Oblast's Central TB Hospital to identify the first 80 eligible participants with available contact information. We operationalised SUD within the constraints of available data in the medical chart, which included either self-reported 'high alcohol consumption' or intravenous drug use at the time of TB diagnosis. We ascertained HIV status and treatment outcomes from clinical records. TB providers, who were not members of the study team, then contacted potential subjects to provide information about the study and refer interested individuals to the study team. Study staff informed interested individuals about study objectives and procedures and how results could potentially inform interventions to improve TB care. In order to reach the desired sample size for HIV and SUD strata, 11 additional eligible participants were identified from hospital records and invited for study participation to replace previously selected individuals with these characteristics who declined participation. We extracted 
Table 1 WHO's five dimensions affecting adherence to long-term therapy*

\begin{tabular}{ll}
$\begin{array}{l}\text { Social and economic } \\
\text { related }\end{array}$ & $\begin{array}{l}\text { Characteristics related to the patient's economic and social position (eg, poverty, illiteracy, } \\
\text { education level) }\end{array}$ \\
\hline $\begin{array}{l}\text { Healthcare team and } \\
\text { system related }\end{array}$ & $\begin{array}{l}\text { Aspects of the system and group of individuals providing condition-related care for the individual (eg, } \\
\text { patient-provider relationship, medication distribution) }\end{array}$ \\
$\begin{array}{l}\text { Therapy related } \\
\text { Patient related }\end{array}$ & $\begin{array}{l}\text { Fesources, knowledge, attitudes, beliefs, perceptions, and expectations of the patient (eg, self- } \\
\text { efficacy), forgetfulness, psychosocial stressors }\end{array}$ \\
Condition related & $\begin{array}{l}\text { Particular illness-related demands faced by the patient (eg, severity of symptoms, level of disability, } \\
\text { rate of disease progression) }\end{array}$ \\
\hline
\end{tabular}

*Table adapted from content from $\mathrm{WHO}^{33}$ framework on adherence.

additional demographic information from the medical records: age, sex, residence and employment status.

\section{Data collection procedures}

A local research team of three members conducted in-person, semistructured interviews in the Russian or Ukrainian language with study participants. Interviews were conducted according to patients' availability from August through October 2015 either at TB clinics or patients' preferred location. Participants were informed of their right to withdraw at any time before, during or after data collection. Interviews lasted 45-60 min. Participants received telephone cards worth US $\$ 3.50$ on interview completion. All interviews were audio recorded, transcribed verbatim and translated into English by qualified translators independently from the interviewers.

We developed the interview guide content to align with the WHO framework for categorising factors influencing adherence to long-term therapies into five dimensions: socioeconomic, health system/healthcare team-related, therapy-related, patient-related and condition-related factors $^{33}$ (table 1). Interview questions were open ended and facilitated elaboration on this framework by exploring adherence motivators and patients' treatment preferences. We also included questions intended to capture patients' perceptions of their own adherence behaviour and TB knowledge. Questions addressed patients' experiences during $\mathrm{TB}$ diagnosis as well as inpatient and outpatient phases of treatment (online supplementary material: interview guide). Interviewers asked follow-up questions when appropriate to elicit additional explanatory and experiential details. The semistructured format was intended to encourage patients to speak broadly on their relevant experience.

\section{Data analysis}

We analysed data to identify and examine thematic content corresponding to questions eliciting details within the aforementioned WHO framework ${ }^{33}$ and additional relevant themes that emerged from participant narratives. The process began with familiarisation by reading transcripts followed by identifying and operationalising themes and subthemes and creating an initial codebook. To improve reliability and intercoder agreement, OA, ED and TK open coded 10 initial transcripts with subsequent comparison of coding patterns and revision of the codebook via consensus. We double coded all interviews in a similar manner and refined the codebook throughout the analysis phase. We coded all transcripts using the finalised codebook and reconciled discordant codes via consensus. All coded segments in the transcript text were organised under major themes and subthemes identified from the data. To evaluate whether HIV and SUD were key drivers of treatment adherence, we examined the occurrence and frequency of themes and subthemes among respondents with HIV or SUD compared with respondents without these comorbidities. We separately compared themes based on participants' treatment completion status. Finally, we selected illustrative excerpts across strata to convey this content in the respondents' own words.

We used NVivo V.11 (QSR International, Cambridge, MA) to facilitate qualitative data analysis.

\section{Patient and public involvement}

Patients were not involved in development of the research questions, study design, interpretation of results or writing of the manuscript.

\section{RESULTS}

Among 91 eligible participants whom we attempted to contact, $60(65.9 \%)$ agreed to participate, $16(17.6 \%)$ declined, $12(13.2 \%)$ could not be reached from available contact information and $3(3.3 \%)$ were unavailable for interview.

Table 2 lists demographic and clinical characteristics of study participants. Nineteen $(32.8 \%)$ participants were HIV positive and 12 (20.3\%) had SUD; among HIVpositive participants, $6(33.3 \%)$ had overlapping SUD. Nine $(15.0 \%)$ individuals did not complete TB treatment and among them, 1 (11.1\%) respectively had HIV and SUD.

Overview of participants' experiences with accessing TB care Participants had experienced various symptoms prior to TB diagnosis (eg, poor sleep and appetite, fevers, malaise, weight loss, cough). For several, these symptoms had 


\begin{tabular}{|c|c|}
\hline & $\begin{array}{l}\text { n (\%) or mean } \\
( \pm S D)\end{array}$ \\
\hline Age & $38.5( \pm 12.4)$ \\
\hline Male & $42(70.0)$ \\
\hline \multicolumn{2}{|l|}{ Substance use disorder } \\
\hline Intravenous drug use ${ }^{\star}$ & $8(13.5)$ \\
\hline High alcohol consumption* & $4(6.8)$ \\
\hline HIV positive† & $19(32.8)$ \\
\hline $\begin{array}{l}\text { Substance use disorder among HIV } \\
\text { positive } \neq\end{array}$ & $6(33.3)$ \\
\hline \multicolumn{2}{|l|}{ Marital status } \\
\hline Married or live-in partner & $28(46.7)$ \\
\hline Single & $15(25.0)$ \\
\hline Divorced & $11(18.3)$ \\
\hline Widowed & $6(10.0)$ \\
\hline \multicolumn{2}{|l|}{ Education } \\
\hline Secondary & $26(43.3)$ \\
\hline Secondary specialised & 20 (33.3) \\
\hline College & $14(23.3)$ \\
\hline Rural residency & $31(51.7)$ \\
\hline Unemployed & $32(53.3)$ \\
\hline Did not complete TB treatment & $9(15.0)$ \\
\hline
\end{tabular}

*Missing observations, $n=1$. †Missing observations, $\mathrm{n}=2$. $\ddagger$ Missing observations, $n=1$. TB, tuberculosis.

persisted for months prior to seeking care. Participants noted a variety of reasons for delayed healthcare seeking including lack of funds for out-of-pocket expenses, a perception that healthcare workers were not competent and prior experience with lack of resources in healthcare facilities. Several respondents described the need for consistent access to affordable medical care in Ukraine; such access was deemed necessary for timely identification of TB and receipt of relevant care.

[We need access] to all [medical services]. [...] especially to emergency ones. And access should be free, so it does not happen that when you need something urgent in the hospital, they tell you-this much money or that much money. (S-35: male, HIV-/no SUD, completed treatment)

Nearly half of respondents described severe or debilitating symptoms as the final push for seeking care.

I was coughing for rather long time. Probably for half a year. I was coughing, but I thought it would disappear. I didn't take it seriously [...] Only when it became obvious, [when the bleeding started], then we called an ambulance and went to the hospital. (S-10: female, HIV-/no SUD, completed treatment)

I felt bad. Well, I had to solve this problem, because it was impossible to continue living and working like that. [...] I physically could not, well... perform my duties anymore. (S-6: female, HIV+/no SUD, completed treatment)

Notably, for majority of participants, once they sought care for their TB-specific symptoms, they received prompt referral to appropriate TB facilities for diagnosis and treatment initiation.

I was diagnosed immediately $[\ldots]$ and I was immediately given the documents and was told to go to [TB hospital] the next day. That is, I was diagnosed in one day. In the ambulatory [clinic]. (S-17: male, HIV-/no SUD, completed treatment)

For a few patients, their path to final TB diagnosis and treatment was lengthy, as exemplified by one participant who described prolonged treatment course for pneumonia prior to $\mathrm{TB}$ treatment.

At first, I was taken to the hospital and was told that I had pneumonia. [...] They were treating me in a wrong way [for two months] and I threw a lot of money down the drain. (S-25: female, HIV-/no SUD, completed treatment)

We organised the main themes identified as principal challenges faced by patients with $\mathrm{TB}$ and factors influencing adherence to DSTB treatment according to the WHO framework for organising barriers to long-term therapy adherence (table 1). We also categorised themes related to facilitators of treatment adherence. We did not identify additional relevant themes that did not align with the WHO framework.

\section{Socioeconomic-related factors \\ Financial cost of TB treatment}

Although TB drugs are free in Ukraine, participants across our sampling strata, and regardless of treatment completion status, discussed various dimensions of the aggregate economic toll of TB treatment. Over half of participants (n=36: $20 \mathrm{HIV}-/$ no SUD, $16 \mathrm{HIV+/SUD;} 30$ completers, 6 non-completers) described a critical need for financial support, which they did not receive, during TB treatment. Generally, patients are unable to work while hospitalised during the intensive treatment phase. However, for 12 participants ( $5 \mathrm{HIV}-/$ no SUD, $7 \mathrm{HIV}+$ /SUD; 10 completers, 2 non-completers), the financial hardship of lost income was prolonged because they remained unemployed for the duration of their treatment.

Furthermore, whereas there is disability/sick leave pay in Ukraine, only six patients described successfully navigating the system to obtain it. Two notable barriers were lack of patient awareness about how to access this support and failure of healthcare providers to inform patients. One participant explained: 
There are doctors who do not inform you that you can perform all paperwork and register for disability group at once, just after starting treatment, and then you will receive some small pension. (S-15: male, HIV-/no SUD, incomplete treatment)

Over half of participants ( $\mathrm{n}=37: 21 \mathrm{HIV}-/$ no SUD, 16 HIV+/SUD; 30 completers, 7 non-completers) described how the financial toll of lost income was exacerbated by additional costs incurred during TB treatment. These included imaging tests and ancillary medicines such as 'hepatoprotectors', which are commonly prescribed in Ukraine to mitigate the toxic effects of TB drugs on the liver. For example, a participant described the financial burden of these additional medications as follows:

The prices of the medicines [...] are cosmic, incredible. You can't make it. Well, at least there is help, when they give TB pills for free; that is good. But the rest of it - the medicines for the liver, vitamins-I bought those myself [...] The ones for the liver are especially expensive [...], all this hit my pockets a little bit. (S30: male, HIV-/no SUD, completed treatment)

Distance and transportation costs to TB treatment facilities represented another major challenge. Trips lasted several hours and cost up to UAH100.00 (approximately US\$4.00) daily. A patient summarised his journeys as follows:

[...] It's faster to get to the United States than to [the TB clinic]. [Laughs]. Here, transportation is the end. Two or three buses! And try to get on one of them! (S-40: male, HIV-/no SUD, completed treatment)

Assuming trips for TB services once weekly, transportation would cost approximately US\$16 monthly, which represents $26 \%$ of the average monthly income of US\$61.40 per rural household in Ukraine in $2014 .{ }^{34}$ Two participants explicitly related transportation costs to their treatment non-adherence. When asked about reasons for incomplete outpatient treatment, one interviewee responded:

I didn't have money to get to the [TB clinic]. [When the doctor asked] Well I told him, I don't have money now to come, I'm in such a crisis, that I don't have any money, nothing. (S-53: male, HIV-/no SUD, incomplete treatment)

Fourteen participants (10 HIV-/no SUD, 4 HIV+/ SUD; 11 completers, 3 non-completers) further described how the financial burden of TB negatively affected their family either because they were primary income earners who were no longer able to provide for their families or had to rely on relatives for financial support.

Well, 7 months, roughly speaking, I was treated for 7 months. [...] I didn't work anywhere. My wife, she [was] on maternity leave. It was really hard financially. (S-15: male, HIV-/no SUD, incomplete treatment)
[...] And, of course, it had an impact, because all the money that was supposed to go to the household, it all went to the hospital. [...] And my sister had to pull this all alone. And it was hard. [...] Of course, the disease affected us. Hard. (S-41: female, HIV+/no SUD, completed treatment)

\section{Health system and healthcare team-related factors}

For many participants, system-level factors related to the TB treatment facilities and the TB care team occurred in tandem and emerged as notable barriers to treatment adherence.

\section{Psychological impact of hospitalisation}

Participants, irrespective of comorbidities or treatment completion status, broadly articulated the challenges of hospital-based care. For instance, 12 participants (8 HIV-/no SUD, $4 \mathrm{HIV+/SUD;} 11$ completers, 1 noncompleter) described the inpatient experience as psychologically difficult due to boredom and prolonged isolation from family. This invoked a sense of alienation likened to imprisonment, even though patients could leave the hospital anytime.

[...] You are just sitting and waiting [in the hospital room.], You can just become crazy. [...] Just sitting at this cage. That's the worst. [...] (S-7: male, HIV-/ SUD, completed treatment)

One male respondent explored how the psychological impact of hospitalisation influenced his willingness to remain in treatment and credited his ultimate compliance with treatment to intermittent opportunities to communicate with family members.

$[\ldots]$ it was difficult to stay in the hospital. You feel there like [you are] incarcerated [...] You want to break free from there, well... You cannot go anywhere... Everything is the same... It was difficult mentally. [...] The only thing that saved me was communication with relatives [pause] on the phone. And sometimes, on the weekends [pause] they came. But besides that-everything is the same, within these four walls, with pills. (S-35: male, HIV-/no SUD, completed treatment)

\section{Hospital conditions}

The psychological toll of hospitalisation was further exacerbated by physical state of the TB hospital for many participants. Twenty-four respondents (17 HIV-/no SUD, $7 \mathrm{HIV+/SUD;} 20$ completers, 4 non-completers) detailed the dehumanising nature of the hospital setting, describing it as dilapidated, unsanitary and lacking basic amenities.

There is nothing comfortable there. [Sighs]. It's just not possible. Well, it's unhuman. For a normal person who lives in a normal home $[\ldots]$ When there are holes in the walls. There are cockroaches everywhere $[\ldots]$, the building itself and all that—it's just terrible! 
All these things shocked me. (S-12: female, HIV+/no SUD, completed treatment)

I got [to the hospital] in winter, and there was no shower room at all. I mean, there is the large room with the cold water, where it is impossible to take a shower $[\ldots]$ This is the hell-hole. (S-52: male, HIV-/ no SUD, completed treatment)

One participant discussed how these conditions might shape patients' willingness to successfully complete TB treatment:

The buildings were awful inside. Surely, it's not unimportant. You know, when you get in a building, where everything is clean and okay, you know, you really want to take care of yourself. And when everything is in bad condition, I can understand some men who tried to go somewhere [else]. Because, you see, even tuberculosis people must have good buildings after all. (S-22: female, HIV-/no SUD, completed treatment)

Ten respondents (4 HIV-/no SUD, $6 \mathrm{HIV+/SUD;} 8$ completers, 2 non-completers) highlighted incidents of drinking in the hospital, seemingly without staff repercussions, and this contributed to the psychological distress of hospitalisation.

At first there were moments [Laughs]. I even wanted to escape [pause] I thought I would not be able to bear all this. Because people really were drinking and doing all possible things [pause] Well, it was very difficult [pause] I remember it as a nightmare, not that much the disease treatment itself as these conditions. (S-12: female, HIV+/no SUD, completed treatment)

One respondent with an SUD explicitly mentioned substance use on the wards as a contributing factor to interrupting hospital treatment, recounting that:

[...] There is such a mess. And these [pause] drug users. It was impossible there both during day and night! It was terrible. A mess, in a word. But you can do nothing [to change the condition] - they are required to provide treatment. (S-31: female, HIV-/ SUD, incomplete treatment)

\section{Healthcare provider attitudes}

Patient interactions with TB care providers were widely identified across sampling strata as another aspect of TB treatment experienced as a challenge to adherence. Just over one-third ( $\mathrm{n}=23: 14 \mathrm{HIV}$-/no SUD, $9 \mathrm{HIV+/SUD;}$ 19 completers, 4 non-completers) of participants characterised interactions as disrespectful, antagonistic and lacking compassion.

There were terrible characters [TB providers], who did not like anybody, no matter what kind of a person you are [...] Yes, I would like to improve the attitude, so that the staff treated the patients more like humans [...]. (S-35: male, HIV-/no SUD, completed treatment)

It's hostile. Awfully hostile. The doctor is just an overseer. Actually, she insults people. [Once], a young girl came with two little children-and [the doctor] was yelling at her so loudly, that, in front of her children, probably the hair rose on her head with fright. This is not a conversation of a doctor and a patient. It is just scary. (S-20: female, HIV-/no SUD, completed treatment)

Among these, seven participants (1 HIV-/no SUD, 6 HIV+/SUD; 6 completers, 1 non-completer) described harsh reactions from healthcare providers after interrupting treatment. Notably, the same respondent who stopped treatment due to the hospital conditions illustrated her experience as follows:

They berated me [...] because I had no right to [stop treatment]. To escape from the hospital, especially as I live among the people [...] They said if I do not go through treatment-just die if you want to [...] They said, 'If you want to get treatment-get it. It is in your best interest. If you do not want to-why would you occupy the [hospital] bed for nothing? You only waste products, let other people take your place.' (S31: female, HIV-/SUD, incomplete treatment)

The rigid implementation of facility-based directly observed therapy (DOT daily, as prescribed by UNTP guidelines, coupled with the authoritative style of TB providers in Ukraine seemed to further strain interactions between providers and patients. Some participants perceived providers as unaccommodating of patients' needs related to the difficulties associated with daily clinic visits and other challenges faced by patients with TB. One participant who had undergone TB treatment twice and struggled with SUD recalled how his negative experience with the TB specialist contributed to his reluctance to complete his first course of treatment.

The most difficult was when I was on out-patient treatment. I had to go every day to see a doctor, to get pills. [...] Well, I did not want to go every day. I had other problems [substance use disorder] [...] Well, for the addicted man, yes. I did not have time. And I had at that time tuberculotherapist, she was still from the Soviet Union. Everything had to be according to schedule-'You must come every day to see me.' And so every day I had quarrels with her. That I was late, then something else. [...] I did not work out relations with the doctor, that's all. Well, she had a quite different approach. [...] Oh, she considered me a garbage. And I with such pride-[went] away. (S-18: male, HIV+/SUD, completed treatment) 


\section{Therapy-related factors}

Pill burden and side effects

Over half (n=33: $22 \mathrm{HIV-/no} \mathrm{SUD,} 11 \mathrm{HIV} / \mathrm{SUD}$; 26 completers and 7 non-completers) of participants discussed the physical challenge of swallowing 8-20 pills at once during the 2-month intensive treatment phase. The pill burden had a negative impact on patients' experience. One participant recalled:

You do not want to take them because the amount of medicines-this is the bunch [shows with his hands] [...] If to put them into plastic glass, it is half a glass of tablets. And it is difficult even physically to take them [at once]. Not speaking about moral difficulties. When a human sees such a number of pills for the first time, he is shocked. [...] It is terrible, it burns, it is unpleasant. You do not want to take them all the time. (S-52: male, HIV-/no SUD, completed treatment)

Whereas participants widely described various TB treatment side effects, for one respondent, her provider's unsupportive response to side effects compounded her negative experience with treatment and served as a barrier to adherence.

The first month, when a severe allergy appeared, [I] even came to the doctor and said-'I'm not going to take it. I will not take it, because well, it's unbearable.' I have already reached the point that I had a nervous breakdown [...] I came, I was not given any reasonable answer. I said I'm not going to take it at all, then I called, they told me to take it anyway. I took... four and a half (months). Then for two weeks I did not take any medicine. (S-4: female, HIV+/SUD status unknown, completed treatment)

\section{Patient-related factors}

TB knowledge

Respondents across our sampling strata expressed an adequate understanding of TB disease. However, whereas a majority of respondents ( $\mathrm{n}=42: 25 \mathrm{HIV}-/$ no SUD, 17 HIV+/SUD; 37 completers, 5 non-completers) knew that TB was transmitted via airborne droplets, many $(n=20$ : $12 \mathrm{HIV}-/$ no SUD, $8 \mathrm{HIV+/SUD;} 17$ completers, 3 noncompleters) also erroneously believed TB transmission occurred via contact with bodily fluids. One participant exemplified this misconception by stating:

There are possible options that $[\mathrm{TB}]$ is transmitted through blood. Definitely. I suspect that it is also possible that it's sexually transmitted; if it's transmitted by airborne droplets, then why can't it be sexually transmitted as well. (S-6: female, HIV+/no SUD, completed treatment)

In addition, many participants (n=26: $15 \mathrm{HIV}-/ \mathrm{no}$ SUD, $9 \mathrm{HIV+/SUD;} 22$ completers, 4 non-completers) conveyed their understanding that missing doses of TB medications could decrease treatment effectiveness or lead to acquisition of resistance. Only one patient expressed this was a motivator of treatment adherence.

I did not have any idea not to take pills. The doctor told me that if I did not take pills, the body would produce resistance to these pills, and the [treatment] would no longer work if I missed at least once. And I did not need this. I wanted effective treatment. (S-23: male, HIV+/SUD, completed treatment)

Notably, the unsupportive communication style of providers adversely influenced the amount and quality of information patients received about TB. We identified five instances of participants discussing how the negative interpersonal relationship with providers discouraged them from seeking information from doctors. Highlighting this experience, one participant noted:

I had bad relations with the doctor. So, I did not always consult with her. Yes, she was rude sometimes $[\ldots]$ she was mean to me [...] She spoke with asperity. Well, she produced an impression-she was not talking with patients, but with passers-by, with the ordinary people from the street. (S-49: female, HIV+/ no SUD, completed treatment)

Negative patient-provider interactions also led these participants to pursue other avenues for information about their TB diagnosis and treatment plan. These negative interactions occurred in the context of other challenges to engaging and completing TB treatment. For example, one female respondent who experienced various painful treatment side effects and initially refused inpatient treatment due to the poor hospital conditions described seeking out TB-related information from other sources to avoid interactions with her healthcare providers.

[...] when I ask a question, I'd like to get an answer from doctors. Without negativity [...] My doctor perceived me with so much negativity. And I don't know why, I treated her fine. [...] I got home, I started reading things myself [on the internet] and got interested. (S-56: female, HIV-/no SUD, completed treatment)

\section{Psychological state}

TB diagnosis itself further compounded the psychological challenges associated with hospital-based TB care. Nineteen participants (13 HIV-/no SUD, $6 \mathrm{HIV}+/$ SUD; 16 completers, 3 non-completers) broadly characterised their experience as psychologically difficult with 11 (7 HIV-/no SUD, 4 HIV+/SUD; 9 completers, 2 non-completers) specifying they experienced feelings of depression and anxiety. These feelings were largely associated with the TB diagnosis and often rooted in patients' fear for their own morbidity but were not clearly linked to treatment adherence.

As [with] every disease, it is some kind of stress for a person. More than that, it's not a flu, it's much more 
serious disease. Of course, psychologically it was hard. (S-48: male, HIV-/no SUD, completed treatment)

\section{Forgetfulness}

Eight participants, all of whom completed treatment ( 5 $\mathrm{HIV}-$ /no SUD, $3 \mathrm{HIV+/SUD),} \mathrm{described} \mathrm{instances} \mathrm{of}$ forgetting to take the pills amidst their daily routines. For example, a respondent explained:

I missed doses a little bit after the hospital. Because of my own fault. Sometimes simply-there was no time, I was busy [...]. (S-47: male, HIV-/no SUD, completed treatment)

\section{Alcohol consumption}

Four respondents with comorbid HIV or SUD (3 completers, 1 non-completer) described alcohol consumption as an individual-level factor that contributed to missed treatment doses. One participant disclosed:

[...] Well, honestly speaking, [...] my friends came to visit me [pause] I took [alcohol] with them and did not want to take the medicines [...] [I] did not take the pills. (S-60: female, HIV-/SUD, completed treatment)

\section{Condition-related factors}

\section{TB-associated stigma}

Participants across our comparison groups regarded TB as a shameful disease that only afflicts certain marginalised populations who engage in socially unacceptable behaviours (eg, injection drug users and prisoners). Twelve participants (9 HIV-/no SUD, $3 \mathrm{HIV+/SUD;}$ 10 completers, 2 non-completers) discussed how the perceived stigma associated with TB led to self-imposed withdrawal and isolation from social networks.

I thought that the people's attitude would change. [...] I have some friends who did not know but suspected that it may be [TB]. When I was at hospital, [...] I bought the new phone number that only my family knew [...]. (S-13: male, HIV-/no SUD, completed treatment)

Other respondents (n=12: $8 \mathrm{HIV}-/$ no SUD, $4 \mathrm{HIV+/}$ SUD; 9 completers, 3 non-completers) described instances of feeling stigmatised and rejected by friends and family after disclosing their TB diagnosis. One participant described how his fear of rejection led him to attempt self-treatment after TB diagnosis.

[...] I just made a decision, because, well, I knew that this thing [TB] will pop up and everyone will abandon me. So, after all I decided to try [treatment] on my own, got into the Internet, found out how everything's done. [...] (S-37: male, HIV+/no SUD, completed treatment)

\section{Facilitators of treatment adherence}

When asked about motivation for continuing treatment, many participants (n=32: $19 \mathrm{HIV}-/$ no SUD, $13 \mathrm{HIV+/}$ SUD; 27 completers, 5 non-completers) described a desire to recover or stay healthy/alive, and some $(\mathrm{n}=12: 6 \mathrm{HIV}-/$ no SUD, 6 HIV+/SUD; 11 completers, 1 non-completer) articulated their understanding of treatment necessity.

I had to overcome this crisis; it was necessary to be treated [...], otherwise-death. I had to get myself together, that's it. And this helped [...]. (S-55: male, HIV-/no SUD, completed treatment)

Only one respondent highlighted encouragement from providers as a facilitator of adherence.

Yes, the regimen. For me it's very hard [...] But thanks to the doctors, $[\ldots]$ they were coming, they were asking me-'did you take your pills?' And that's why I did not skip. (S-27: female, HIV+, SUD, completed treatment)

Participants suggested various things that might have mitigated their negative treatment experience. Twentyseven respondents (14 HIV-/no SUD, 13 HIV+/SUD; 24 completers, 3 non-completers) preferred the comfort of home-based treatment.

Well, everything is easier at home [...] Hospital is a hospital-everyone is sick there, and it's better to recover at home, with the family [...]. (S-2: male, SUD, completed treatment)

Although psychoemotional support was not routinely available, respondents ( $\mathrm{n}=21: 13 \mathrm{HIV}-/$ no SUD, $8 \mathrm{HIV+}$ ) SUD; 19 completers, 2 non-completers) broadly expressed an important need for such support, particularly during hospitalisation.

[...] psychological support, [...] is necessary by $100 \%$. [In the TB hospital] it is very difficult without it. If to remember, there is no one in the ward to speak to [pause] As you do not know anyone [...]. (S-13: male, HIV-/no SUD, completed treatment)

\section{DISCUSSION}

We identified structural barriers related to centralised, facility-based TB services and economic impacts of treatment, provider communication styles, the psychological toll of TB, as well as treatment pill burden as prominent challenges faced by patients treated for DSTB in Ukraine. These challenges emerged as factors that undermine treatment adherence and are consistent with identified adherence barriers in other sociopolitical contexts, thus suggesting that interventions implemented successfully elsewhere would be appropriate for consideration in Ukraine. A recent qualitative study among patients with TB in Ukraine similarly identified the inconvenience and cost of clinic-based DOT during the ambulatory phase of treatment as major challenges to treatment adherence. ${ }^{31}$ 
Our study provides additional insights into how hospitalisation and patient interactions with $\mathrm{TB}$ providers adversely influence adherence in the context of TB services in Ukraine. We also found commonalities in the challenges faced by patients with TB with and without risk factors for non-adherence. Hence, interventions to improve TB care in Ukraine will likely have a broad impact on all patients with TB.

We identified various dimensions of TB care in Ukraine that undermine patient commitment to TB treatment. Many participants described their negative experience of hospitalisation, including the degrading infrastructure and the isolating hospital environment, as a major source of distress and deterrent to treatment, and nearly half of participants expressed a preference for home-based TB treatment. A recent study from Latvia, with similar organisation of TB services, revealed that initiating TB treatment in a demoralising hospital setting adversely affected patients' willingness to adhere to a prolonged treatment course. $^{29}$ The rigid expectation of facility-based DOT throughout the ambulatory phase of treatment in Ukraine further compromised patients' ability to complete treatment. This expectation disregards associated barriers that undermine healthcare-seeking behaviour, such as time and cost of daily transport. A prior analysis of UNTP has concluded that hospital-based TB care contributes to poor outcomes, ${ }^{30}$ and the latest UNTP guidelines recommend outpatient management of DSTB. ${ }^{12}$ Moreover, a pilot study in Ukraine recently reported home-based DOT facilitated retention in TB care. ${ }^{31}$ Ongoing reorganisation of TB care in Ukraine will provide opportunities to assess how full-scale implementation of home-based DSTB treatment influences patients' experiences and treatment outcomes.

We also found that many patients with TB reported strikingly negative attitudes towards providers. The harsh, rigid style of TB providers in Ukraine compromised patient willingness to continue treatment and led to missed opportunities for providers to convey information about TB and the importance of TB therapy. Studies in other sociopolitical contexts have shown poor patient-provider interactions contribute to TB treatment non-adherence. ${ }^{27} 2835$ Notably, studies from former Soviet Union countries have specifically demonstrated that the authoritative communication styles of TB providers in these settings can undermine patient autonomy and readiness to comply with treatment recommendations. ${ }^{27} 28$ There is ample evidence that patient-provider relationships characterised by trust, mutual respect and shared decision-making facilitate adherence to chronic disease therapy. ${ }^{27}{ }^{36-38} \mathrm{~A}$ recent evaluation of a social support programme for patients with TB in Ukraine reported that excellent rapport and communication marked by respect and empathy from nurses was a key driver of success in patient retention. ${ }^{31}$ Given the psychological difficulties associated with $\mathrm{TB}$, more supportive attitudes from providers might improve patient willingness to remain in care.
Participants described psychological distress associated with TB diagnosis, and many voiced their desire for psychological support during treatment. Studies have similarly found high prevalence of depression and anxiety among patients with $\mathrm{TB}^{25} 35$ 39; such negative emotional states contribute to non-adherence. ${ }^{40}$ At the same time, treatment of psychiatric comorbidities increases TB treatment adherence, ${ }^{39}$ and psychosocial support improves treatment success rates. ${ }^{41}$ Given TB diagnosis itself might render patients emotionally distraught, integration of psychoemotional care with TB treatment in Ukraine might help patients better confront the challenges that undermine adherence.

Many participants discussed the economic burden of TB treatment. Poverty is a risk factor for TB disease, and TB treatment exacerbates existing financial hardship and impairs treatment adherence. ${ }^{25} 273143-45$ Studies have shown that cash transfers, and assistance with food and transport can increase treatment success rates. ${ }^{41}{ }^{46}$ Recent evidence from Ukraine has demonstrated the success of a pilot intervention of socioeconomic support in reducing risk of loss to follow-up among high-risk patients with TB. ${ }^{31}{ }^{47}$ Efforts to alleviate the financial consequences of TB in Ukraine can also focus on raising awareness to increase access to existing sick/disability pay. We also note evidence from chronic diseases, including HIV, indicates peer support groups can promote positive behaviours necessary for retention in care. ${ }^{3348} 49$ A previous qualitative study among patients with TB in Uzbekistan found support and encouragement from peers and family members was a motivating factor to remain in treatment. ${ }^{27}$ Hence, in addition to direct economic support, establishing social support networks using community members may represent a low-cost intervention that could increase adherence to TB treatment in Ukraine. ${ }^{33}$

Furthermore, our study findings are consistent with other research that pill burden represents an important barrier to TB treatment adherence. ${ }^{19} 35$ As fixed-dose combination (FDC) pills reduce TB treatment pill burden, the WHO recognises higher patient satisfaction as an advantage of FDCs and recommends their use in TB programmes. ${ }^{50}$ Procurement of FDCs in Ukraine might improve patients' experience with TB treatment. We also note the lack of evidence supporting the benefit of hepatoprotective agents with $\mathrm{TB}$ therapy. ${ }^{51}$ Their ongoing use in Ukraine adds to TB treatment pill burden and increases patients' expenses without a clear benefit.

Among individual-level factors assessed, we did not identify health literacy as a principal driver of adherence, despite evidence in similar contexts that low TB knowledge adversely affects treatment adherence. ${ }^{27} 28$ We found low knowledge about TB transmission modes though could not directly link this to treatment adherence. Many participants also acknowledged the negative consequences of missing TB treatment doses, but this did not emerge as a main facilitator of treatment adherence. In contrast, qualitative studies among patients with TB in Eastern Europe have found that incorrect information 
about TB treatment, disseminated through lay community networks, contributed to non-adherence whereas knowledge and belief in the effectiveness of TB therapy as well as increased patient awareness about importance of treatment facilitated adherence. ${ }^{27} 28$

Notably, we did not identify themes that distinguish non-completers nor illuminate unique reasons for incomplete treatment. Whereas certain factors, such as treatment cost and pill burden, were identified as barriers in majority of non-completers (seven of nine for each), these factors were also identified by approximately half of completers. Indeed, each barrier to adherence identified affected both completers and non-completers. While participants were largely motivated to undergo treatment to remain healthy, we identified few facilitators of $\mathrm{TB}$ treatment adherence. Our findings suggest that patients with $\mathrm{TB}$, with and without risk factors for non-adherence, broadly encounter structural challenges within Ukraine's TB care delivery system that undercut their motivation for adherence.

\section{Policy and practice implications}

Our findings highlight two major opportunities for changes in Ukraine's TB programme targeted at delivering patient-centred care and improving TB treatment outcomes. First, similar to other assessment of TB services in this region, ${ }^{29}$ we found that highly centralised care and facility-based DOT undermine patient ability to remain in treatment. Whereas DOT focuses on medical care to achieve TB cure, there is increasing recognition of the need to integrate such medical services with financial and psychosocial support. Low socioeconomic status broadly undermines healthcare-seeking behaviour and it is well known that poverty elevates risk of TB disease, which in turn renders patients poorer. ${ }^{25} 273143-45$ Thus, TB control efforts in this setting must address socioeconomic factors that put patients at higher risk for TB and undercut their will to remain in care. Successful programmes of socioeconomic and psychoemotional support for patients with TB have been documented in Ukraine and similar contexts in Eastern Europe. ${ }^{314152}$ Hence scale-up of such programmes can be considered for broad adoption in Ukraine.

Second, we identified how negative provider-patient relationships adversely impact treatment adherence. Raising awareness and training TB providers on patient-centred communication styles and collaborative approaches that promote patient ownership in treatment should be a priority for TB control efforts in Ukraine. Targeted provider training on effective strategies (eg, establishing reminder systems) that promote TB treatment adherence ${ }^{314148}$ might also be useful in this setting. Efforts should also include support for providers to mitigate challenges that might influence their interpersonal communication with patients.

\section{Limitations}

Our study has notable limitations. It is possible our interviewers or interview guide did not sufficiently probe how patients' TB knowledge influences treatment adherence. We focused only on patients' perspectives about TB treatment without exploring providers' viewpoints. Future research efforts can investigate providers' experience to elucidate additional factors that influence TB treatment adherence in this context. TB providers approached eligible patients to provide them with study information and interviews frequently occurred in clinical settings despite offering participants their preferred choice of interview location. Although study staff informed participants that their decision to participate would not impact their future receipt of healthcare services and that the TB care providers would not be granted access to interview details, it remains possible that hospital-based recruitment and data collection may have resulted in selection bias. Our study results reflect a range of positive and negative descriptions of treatment settings and patientprovider interactions suggesting that patients did not feel obliged to only present a positive portrayal of their TB treatment experience. Lastly, our study sample was purposively selected for maximal variation in factors known to impact TB treatment adherence within only one region of Ukraine and thus may not be representative of the full spectrum of patients with TB in Ukraine or of patients who receive care from private providers. Nonetheless, we believe that our study sample represents a substantial portion of the TB patient population, including those at particular risk for poor outcomes, and thus can inform approaches to support treatment adherence that are widely applicable.

\section{CONCLUSION}

We document a qualitative assessment of patients' experiences during $\mathrm{TB}$ treatment in Ukraine and identify targets for interventions that may improve TB treatment outcomes. Challenges that undermine treatment adherence were not unique to patients at highest risk for non-adherence, thus incorporating patient-centred approaches into TB control efforts will likely have a broad impact in Ukraine.

\section{Author affiliations}

${ }^{1}$ Internal Medicine, McGovern Medical School at the University of Texas Health Science Center - Houston, Houston, Texas, USA

${ }^{2}$ Psychiatry, University of California San Francisco, San Francisco, California, USA

${ }^{3}$ Ukrainian Institute on Public Health Policy, Kyiv, Ukraine

${ }^{4} \mathrm{PH}$ Capital. Public Health Experts, Kyiv, Ukraine

${ }^{5}$ Infectious Diseases, The Miriam Hospital, Warren Alpert School of Medicine at Brown University, Providence, Rhode Island, USA

${ }^{6}$ Phthisiology (Tuberculosis), Bogomolets National Medical University, Kyiv, Ukraine ${ }^{7}$ Department of Global Health and Social Medicine, Harvard Medical School, Boston, Massachusetts, USA

Acknowledgements The authors are grateful to all the participating patients and TB staff in Kyiv Oblast. The authors also thank the interviewers, Olena Zublenko, Svitlana Gatchenko and Oleg Kurdin, as well as Gay Bronson for their contribution.

Contributors MBM, OA, AEB and TPF led the study design. VP oversaw acquisition of data in conjunction with $\mathrm{OA}, \mathrm{TK}, \mathrm{OM}, \mathrm{MB}$ and NR. OA, ED and TK conducted the analysis and interpretation of data with supervision by AEB. OA and ED wrote the first draft of the manuscript, and all authors contributed to revision of the 
manuscript for important intellectual content. All authors had full access to all of the data in the study and can take responsibility for the integrity of the data and the accuracy of the data analysis.

Funding This work was supported by the National Institute on Drug Abuse (NIDA) (T32DA013911 to OA and ED; R25DA037190-04 to ED), the National Institute of Mental Health and the Brown Initiative in HIV and AIDS Clinical Research for Minority Communities (R25MH083620 to OA).

Disclaimer The funding sources had no role in the study design, in the collection, analysis and interpretation of data, in the writing of the report or in the decision to submit the manuscript for publication.

Competing interests None declared.

Patient consent for publication Not required.

Ethics approval The study was approved by the Institutional Review Board at The Miriam Hospital, Lifespan, Providence, RI [204815 45CFR 46.110(7)] and the Research Ethics Committee at Bogomolets Medical University, Kyiv, Ukraine (No. 86). All participants provided written informed consent.

Provenance and peer review Not commissioned; externally peer reviewed.

Data availability statement Data are available upon reasonable request. Given the sensitive nature of this qualitative research and the possibility of identifying respondents, we are not able to make raw interview transcripts available in a public repository. However, we are willing to make portions of translated transcripts (with any identifying information redacted) available upon reasonable request. Interested persons should contact the corresponding author.

Open access This is an open access article distributed in accordance with the Creative Commons Attribution Non Commercial (CC BY-NC 4.0) license, which permits others to distribute, remix, adapt, build upon this work non-commercially, and license their derivative works on different terms, provided the original work is properly cited, appropriate credit is given, any changes made indicated, and the use is non-commercial. See: http://creativecommons.org/licenses/by-nc/4.0/.

\section{ORCID iD}

Omowunmi Aibana http://orcid.org/0000-0003-0665-5393

\section{REFERENCES}

1 World Health Organization. Global tuberculosis report, 2019. Available: http://www.who.int/tb/publications/global_report/en/ [Accessed 28 Oct 2019].

2 World Health Organization. Tuberculosis country profiles. Available: http://www.who.int/tb/country/data/profiles/en/ [Accessed 28 Oct 2019].

3 Rechel B, Richardson E, McKee M. Editors. trends in health systems in the former Soviet countries. Observatory studies series, no. 35. Copenhagen (Denmark): European Observatory on health systems and policies, 2014. Available: https://www.ncbi.nlm.nih.gov/books/ NBK458305/ [Accessed 28 Oct 2019].

4 Koch E. Local Microbiologies of tuberculosis: insights from the Republic of Georgia. Med Anthropol 2011;30:81-101.

5 Koch E. Tuberculosis is a threshold: the making of a social disease in Post-Soviet Georgia. Med Anthropol 2013;32:309-24.

6 Altice FL, Azbel L, Stone J, et al. The perfect storm: incarceration and the high-risk environment perpetuating transmission of HIV, hepatitis $\mathrm{C}$ virus, and tuberculosis in eastern Europe and central Asia. Lancet 2016;388:1228-48.

7 Droznin M, Johnson A, Johnson AM. Multidrug resistant tuberculosis in prisons located in former Soviet countries: a systematic review. PLoS One 2017;12:e0174373.

8 Jolley E, Rhodes T, Platt L, et al. Hiv among people who inject drugs in central and eastern Europe and central Asia: a systematic review with implications for policy. BMJ Open 2012;2:e001465.

9 Gökengin D, Oprea C, Uysal S, et al. The growing HIV epidemic in central Europe: a neglected issue? J Virus Erad 2016;2:156-61.

10 Atun R, Olynik I. Resistance to implementing policy change: the case of Ukraine. Bull World Health Organ 2008;86:147-54.

11 Public Health Center of the Ministry of Health of Ukraine. Tuberculosis in Ukraine analytical and statistical reference book, 2017. Available: https://www.phc.org.ua/sites/default/files/uploads/ files/PATH_booklet_003-4.pdf [Accessed 28 Oct 2019].

12 Ministry of health of Ukraine, unified clinical protocol for primary, secondary (specialized) and tertiary (highly specialized) medical care for adults with tuberculosis, 2014. Available: https://old.phc.org.ua/ uploads/files/dn_20141231_1039dod.pdf [Accessed 28 Oct 2019].
13 World Health Organization. The end TB strategy. global strategy and targets for tuberculosis prevention, care and control after, 2015. Available: https://www.who.int/tb/strategy/End_TB_Strategy.pdf? ua $=1$ [Accessed 28 Oct 2019].

14 Lytvynenko N, Cherenko S, Feschenko Y, et al. Management of multiand extensively drug-resistant tuberculosis in Ukraine: how well are we doing? Public Health Action 2014;4:67-72.

15 Aibana O, Bachmaha M, Krasiuk V, et al. Risk factors for poor multidrug-resistant tuberculosis treatment outcomes in Kyiv Oblast, Ukraine. BMC Infect Dis 2017;17:129.

16 Kliiman K, Altraja A. Predictors and mortality associated with treatment default in pulmonary tuberculosis. Int J Tuberc Lung Dis 2010;14:454-63.

17 Mitruka K, Winston CA, Navin TR. Predictors of failure in timely tuberculosis treatment completion, United States. int $j$ tuberc lung dis 2012;16:1075-82.

18 Jenkins HE, Ciobanu A, Plesca V, et al. Risk factors and timing of default from treatment for non-multidrug-resistant tuberculosis in Moldova. int $j$ tuberc lung dis 2013;17:373-80.

19 Amuha MG, Kutyabami P, Kitutu FE, et al. Non-adherence to anti-TB drubs among TB/HIV co-infected patients in Mbarara Hospital Uganda: prevalence and associated factors. Afr Health Sci 2009:S8-15.

20 Caylà JA, Rodrigo T, Ruiz-Manzano J, et al. Tuberculosis treatment adherence and fatality in Spain. Respir Res 2009;10:121.

21 Bhagat VM, Gattani PL. Factors affecting tuberculosis retreatment defaults in Nanded, India. Southeast Asian J Trop Med Public Health 2010:41:1153-7.

22 Muture BN, Keraka MN, Kimuu PK, et al. Factors associated with default from treatment among tuberculosis patients in Nairobi Province, Kenya: a case control study. BMC Public Health 2011;11:696.

23 Burton NT, Forson A, Lurie MN, et al. Factors associated with mortality and default among patients with tuberculosis attending a teaching hospital clinic in Accra, Ghana. Trans $R$ Soc Trop Med Hyg 2011;105:675-82.

24 Ifebunandu NA, Ukwaja KN. Tuberculosis treatment default in a large tertiary care hospital in urban Nigeria: prevalence, trend, timing and predictors. J Infect Public Health 2012;5:340-5.

25 Lohiniva AL, Mokhtar A, Azer A, et al. Qualitative interviews with non-national tuberculosis patients in Cairo, Egypt: understanding the financial and social cost of treatment adherence. Health Soc Care Community 2016;24:e164-72.

26 de Vries SG, Cremers AL, Heuvelings CC, et al. Barriers and facilitators to the uptake of tuberculosis diagnostic and treatment services by hard-to-reach populations in countries of low and medium tuberculosis incidence: a systematic review of qualitative literature. Lancet Infect Dis 2017;17:e128-43.

27 Horter S, Stringer B, Greig J, et al. Where there is hope: a qualitative study examining patients' adherence to multi-drug resistant tuberculosis treatment in Karakalpakstan, Uzbekistan. BMC Infect Dis 2016;16:362.

28 Stringer B, Lowton K, Tillashaikhov M, et al. 'They prefer hidden treatment': anti-tuberculosis drug-taking practices and drug regulation in Karakalpakstan. int $j$ tuberc lung dis 2016;20:1084-90.

29 Kielmann K, Vidal N, Riekstina V, et al. "Treatment is of primary importance, and social assistance is secondary": A qualitative study on the organisation of tuberculosis (TB) care and patients' experience of starting and staying on TB treatment in Riga, Latvia. PLoS One 2018;13:e0203937.

30 World Health Organization, Regional Office for Europe. Review of the National tuberculosis programme in Ukraine 10-22 October, 2010. Available: http://www.euro.who.int/en/countries/ukraine/ publications $3 /$ review-of-the-national-tuberculosis-programme-inukraine [Accessed 28 Oct 2019].

31 Charyeva Z, Curtis S, Mullen S, et al. What works best for ensuring treatment adherence. lessons from a social support program for people treated for tuberculosis in Ukraine. PLOS One 2019;14:e0221688.

32 World Health Organization. A patient-centered approach to TB care, 2018. Available: https://apps.who.int/iris/bitstream/handle/10665/ 272467/WHO-CDS-TB-2018.13-eng.pdf?ua=1 [Accessed 28 Oct 2019].

33 The World Health Organization. Adherence to long-term therapies: evidence for action. who, 2003. Available: http://whqlibdoc.who.int/ publications/2003/9241545992.pdf [Accessed 28 Oct 2019].

34 Ukrainian State Statistical Services,. Expenditures and resources of households of Ukraine in year 2014, Kyiv, 2015. Available: https:// ukrstat.org/uk/druk/publicat/Arhiv_u/17/Arch_vrd_zb.htm [Accessed 28 Oct 2019]. 
35 Gebremariam MK, Bjune GA, Frich JC. Barriers and facilitators of adherence to TB treatment in patients on concomitant TB and HIV treatment: a qualitative study. BMC Public Health 2010;10:651.

36 Young HN, Len-Rios ME, Brown R, et al. How does patient-provider communication influence adherence to asthma medications? Patient Educ Couns 2017;100:696-702.

37 Schoenthaler A, Knafl GJ, Fiscella K, et al. Addressing the social needs of hypertensive patients: the role of patient-provider communication as a predictor of medication adherence. Circ Cardiovasc Qual Outcomes 2017;10:e003659.

38 Sohal T, Sohal P, King-Shier KM, et al. Barriers and facilitators for type-2 diabetes management in South Asians: a systematic review. PLoS One 2015;10:e0136202.

39 Pachi A, Bratis D, Moussas G, et al. Psychiatric morbidity and other factors affecting treatment adherence in pulmonary tuberculosis patients. Tuberc Res Treat 2013;2013:1-37.

40 Tola HH, Tol A, Shojaeizadeh D, et al. Tuberculosis treatment nonadherence and lost to follow up among TB patients with or without HIV in developing dountries: a systematic review. Iran J Public Health 2015;44:1-11.

41 van Hoorn R, Jaramillo E, Collins D, et al. The effects of PsychoEmotional and socio-economic support for tuberculosis patients on treatment adherence and treatment outcomes - a systematic review and meta-analysis. PLoS One 2016;11:e0154095.

42 Gelmanova IY, Taran DV, Mishustin SP, et al. 'Sputnik': a programmatic approach to improve tuberculosis treatment adherence and outcome among defaulters. int $j$ tuberc lung dis 2011;15:1373-9.

43 Mauch V, Bonsu F, Gyapong M, et al. Free tuberculosis diagnosis and treatment are not enough: patient cost evidence from three continents. int $j$ tuberc lung dis 2013;17:381-7.

44 Chida N, Ansari Z, Hussain H, et al. Determinants of default from tuberculosis treatment among patients with drug-susceptible tuberculosis in Karachi, Pakistan: a mixed methods study. PLoS One 2015;10:e0142384.

45 Paz-Soldán VA, Alban RE, Jones CD, et al. The provision of and need for social support among adult and pediatric patients with tuberculosis in Lima, Peru: a qualitative study. BMC Health Serv Res 2013;13:290.

46 Andrade KVFde, Nery JS, Souza RAde, et al. Effects of social protection on tuberculosis treatment outcomes in low or middleincome and in high-burden countries: systematic review and metaanalysis. Cad Saúde Pública 2018;34:e00153116.

47 Priedeman Skiles M, Curtis SL, Angeles G, et al. Evaluating the impact of social support services on tuberculosis treatment default in Ukraine. PLoS One 2018;13:e0199513.

48 Rachlis B, Naanyu V, Wachira J, et al. Identifying common barriers and facilitators to linkage and retention in chronic disease care in Western Kenya. BMC Public Health 2016;16:741.

49 Kanters S, Park JJH, Chan K, et al. Use of peers to improve adherence to antiretroviral therapy: a global network meta-analysis. $J$ Int AIDS Soc 2016;19:21141.

50 World Health Organization. Treatment of tuberculosis: guidelines for treatment of drug-susceptible tuberculosis and patient care. 2017 update. Available: https://apps.who.int/iris/bitstream/handle/10665/ 255052/9789241550000-eng.pdf?sequence $=1$ [Accessed 28 Oct 2019].

51 Saito Z, Kaneko Y, Kinoshita A, et al. Effectiveness of hepatoprotective drugs for anti-tuberculosis drug-induced hepatotoxicity: a retrospective analysis. BMC Infect Dis 2016;16:668.

52 Gärden B, Samarina A, Stavchanskaya I, et al. Food incentives improve adherence to tuberculosis drug treatment among homeless patients in Russia. Scand J Caring Sci 2013;27:117-22. 